\title{
Влияние состава слоёв металлизации и отжига в формовочном газе на параметры барьеров Шоттки на основе In0.52Al0.48As
}

\author{
И.Ю. Гензе ${ }^{1}$, М.С. Аксенов ${ }^{2}$, Н.А. Валишева ${ }^{2}$, Д.В. Дмитриев ${ }^{2}$ \\ ${ }^{1}$ Новосибирский государственный университет, Новосибирск, 630090, Пирогова 2 \\ ${ }^{2}$ ИФП им. А.В. Ржанова, Новосибирск, 630090, пр. Ак. Лаврентьева 13 \\ тел:+7 (383) 330-8807, эл. почта:aksenov@isp.nsc.ru
}

DOI 10.34077/RCSP2021-37

Барьер Шоттки $\mathrm{Ti} / \mathrm{n}(\mathrm{i})-\mathrm{In}_{0.52} \mathrm{Al}_{0.48} \mathrm{As}$ (БШ) используется при создании микроволновых фотодетекторов с широким оптическим диапазоном [1]. Свойства используемых БШ при этом определяют ряд рабочих характеристик, стабильность и надёжность производимых приборов.

Традиционным способом изменения параметров БШ, таких как коэффициент идеальности $(n)$ и высота барьера $\left(\varphi_{b}\right)$, является отжиг. Отжиг Ti/InAlAs БШ изучен недостаточно: работы [2,3], посвящённые его анализу, демонстрируют противоречивые результаты, что препятствует формулированию однозначных выводов о его влиянии на параметры исследуемых БШ.

Таким образом, для улучшения технологии производства СВЧ фотодетекторов с требуемыми характеристиками, необходимо установление характерного влияния температуры и времени отжига в формовочном газе $\left(5 \% \mathrm{H}_{2}, 95 \% \mathrm{~N}_{2}\right)$ на параметры $\left(\varphi_{b}, n\right) \mathrm{Au} / \mathrm{Ti} / \mathrm{n}-\mathrm{In}_{0.52} \mathrm{Al}{ }_{0.48} \mathrm{As} / \mathrm{InP}$ и $\mathrm{Au} / \mathrm{Pt} / \mathrm{Ti} / \mathrm{n}$ $\mathrm{In}_{0.52} \mathrm{Al}_{0.48} \mathrm{As} / \mathrm{InP}$ барьеров Шоттки.

В данной работе было установлено влияние отжига различной продолжительности при температурах $300,350,400{ }^{\circ} \mathrm{C}$ на параметры Ti/InAlAs БШ.

Во первых, в рамках теории термоэлектронной эмиссии был проведён анализ прямых ветвей ВАХ и расчёт параметров $\left(\varphi_{b}, n\right) \operatorname{Au}(200 \mathrm{Hм}) / \mathrm{Ti}(20 \mathrm{Hм}) / \mathrm{InAlAs}$ барьеров Шоттки в зависимости от температуры отжига в формовочном газе. Показано, что отжиг БШ при температурах до $350{ }^{\circ} \mathrm{C}$ может быть использован для увеличения изначально низкой (менее 0.6 эВ) высоты барьера до значения 0.69 эВ типичного для данных контактов [4]. Такое изменение может быть связано со взаимодействием титана со слоем собственного оксида InAlAs, что приводит к окислению Ті и образованию соединений $\mathrm{TiO}_{x}$. Показано, что отжиг при больших температурах приводит к резкой деградации параметров и разрушению БШ, что может быть вызвано диффузией Аu через тонкий $(20$ нм) слой Тi $[2,3]$.

Во вторых, проведён аналогичный анализ прямых ветвей BAX и расчёт параметров для $\operatorname{Au}(200$ нм)/Ti(80 нм)/InAlAs и $\mathrm{Au}(200$ нм)/Pt(30 нм)/Ti(80 нм)/InAlAs барьеров Шоттки. Показано, что увеличение толщины Ті и добавление слоя Рt позволяет существенно увеличить как температуру, так и времена отжига. Установлено, что отжиг Ti/InAlAs барьеров Шоттки с изначально высокой высотой барьера (0.68-0.7 эВ) при температурах до $350{ }^{\circ} \mathrm{C}$ суммарной длительностью до 20 минут практически не приводит к изменениям параметров, тогда как с повышением температуры до $400{ }^{\circ} \mathrm{C}$ после $10-20$ минут отжига наблюдается существенное увеличение высоты барьера на 0.04 эВ до значений 0.72-0.73 эВ. Коэффициент идеальности при этом также увеличивается с 1.1 до 1.3. Подобное изменение параметров может быть связано с активацией реакции ведущей к образованию на границе раздела слоя TiAs [2].

\section{Лumepamypa}

[1] Chizh A. L. et al. High-Power High-Speed Schottky Photodiodes for Analog Fiber-Optic Microwave Signal Transmission Lines //Technical Physics Letters. - 2019. - T. 45. - №. 7. - C. 739-741.

[2] Wang L., Adesida I. Schottky barrier characteristics and interfacial reactions of Ti on $\mathrm{n}-\mathrm{In}_{0.52} \mathrm{Al}_{0.48} \mathrm{As}$ //Applied physics letters. - 2007. - T. 91. - №. 2. - C. 022110.

[3] Lien Y. C. et al. Thermal stability of $\mathrm{Ti} / \mathrm{P} t \mathrm{Cu}$ Schottky contact on InAlAs layer //Applied physics letters. $-2006 .-$ T. 89. - №. 8. - C. 083517.

[4] Chistokhin I. B. et al. Barrier characteristics and interface properties of Au/Ti/n-InAlAs Schottky contacts //Materials Science in Semiconductor Processing. - 2018. - T. 74. - C. 193-198. 